\title{
Lymphohaematopoietic malignancy around all industrial complexes that include major oil refineries in Great Britain
}

\author{
P Wilkinson, B Thakrar, P Walls, M Landon, S Falconer, C Grundy, P Elliott
}

Department of Public Health and Policy, London School of Hygiene and Tropical Medicine, Keppel Street, London WC1E 7HT, UK P Wilkinson B Thakrar P Walls

M Landon

C Grundy

Small Area Health Statistics Unit, Department of Epidemiology and Public Health, Imperial College School of Medicine, St Mary's Campus, Norfolk Place, London, W2 1PG, UK

$S$ Falconer

P Elliott

Correspondence to: Dr Paul Wilkinson, Environmental Epidemiology Unit, London School of Hygiene and Tropical Medicine, Keppel Street, London WC1E 7HT. Telephone 0044171927 2444; fax 0044171580 4524; email

p.wilkinson@1shtm.ac.uk

Accepted 22 April 1999

\begin{abstract}
Objectives-To examine the incidence of lymphohaematopoietic malignancy around industrial complexes that include major oil refineries in Great Britain after recent public and scientific concern of possible carcinogenic hazards of emissions from the petrochemical industry.

Methods-Small area study of the incidence of lymphohaematopoietic malignancies, 1974-91, within $7.5 \mathrm{~km}$ of all 11 oil refineries (grouped into seven sites) in Great Britain that were operational by the early 1970s and processed more than two million tonnes of crude oil in 1993.

Results-Combined analysis of data from all seven sites showed no significant $(p<0.05)$ increase in risk of these malignancies within $2 \mathrm{~km}$ or $7.5 \mathrm{~km}$. Hodgkin's lymphoma, but no other malignancy, showed evidence $(p=0.02)$ of a decline in risk with distance from refineries, but there was an apparent deficit of cases of multiple myeloma near the refineries $(\mathrm{p}=0.04)$.

Conclusion-There was no evidence of association between residence near oil refineries and leukaemias, or nonHodgkin's lymphoma. A weak positive association was found between risk of Hodgkin's disease and proximity to major petrochemical industry, and a negative association with multiple myeloma, which may be chance findings within the context of multiple statistical testing.

(Occup Environ Med 1999;56:577-580)
\end{abstract}

Keywords: small area; lymphohaematopoietic malignancy; oil refineries

Oil refining and other petrochemical processes may lead to low level emissions of compounds with possible carcinogenic potential including benzene ${ }^{1}$ and 1,3-butadiene. ${ }^{2}$ A cohort study in the United Kingdom of mortality among oil refinery workers, who would be expected to have higher exposures to these compounds than residential populations, has not shown an excess risk of leukaemia or other haematopoietic malignancy. ${ }^{3}$ Few studies of cancer risks among residential populations living near to petrochemical industry have been reported. A United States study found high rates of cancer of the lung, nasal cavity and sinuses, and skin among the resident male population in counties where the petroleum industry is most heavily concentrated, but no significant in- crease for lymphohaematopoietic malignancy. ${ }^{4}$ Another study in the United States suggested high rates of lung cancer near petrochemical plants. ${ }^{5}$ A study of the geographical distribution of childhood leukaemia and other childhood cancers in Great Britain reported a tendency for clustering near emission sources of (among other things) volatile petroleum products, ${ }^{6}$ although the methodology of this study with residential post codes as a proxy for populations had previously been questioned. ${ }^{7}$ A more recent study of the same data set similarly found an association of childhood cancers with emission sources based on comparisons between address at birth and at death. ${ }^{8}$ By contrast, studies of cancer incidence and mortality among residents living close to a petrochemical plant in south Wales were largely reassuring. ${ }^{9}{ }^{10}$ We report here a study of lymphohaematopoietic malignancy around all industrial complexes that include major oil refineries in Great Britain.

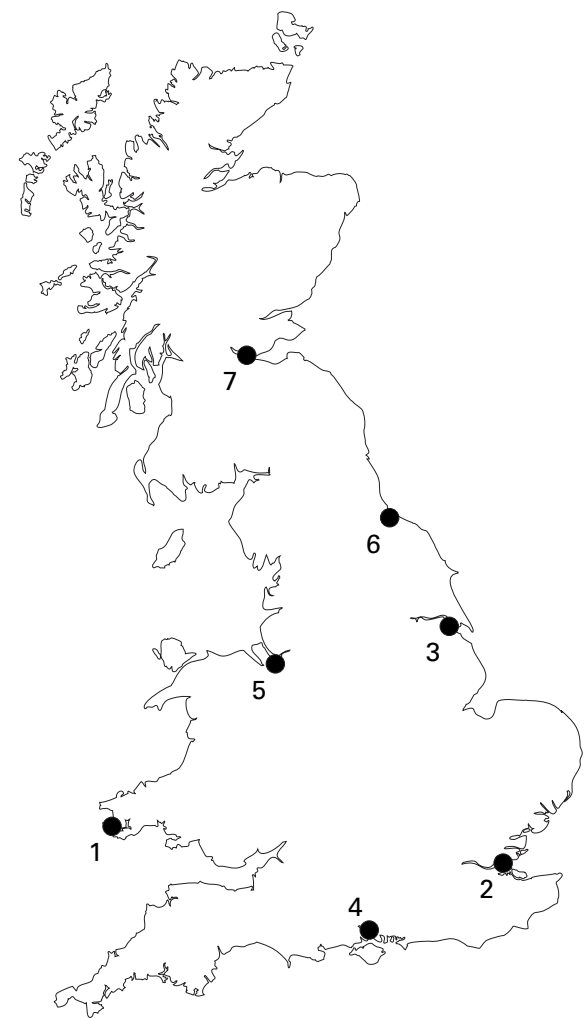

The seven oil refinery sites. (1) Milford Haven (three refineries: Elf, Texaco and PCC, and Gulf); (2) Coryton (two refineries: Mobil and Shell); (3) Immingham (two refineries: Lindsey and Conoco); (4) Esso, Fawley; (5) Shell, Stanlow; (6) Phillips Imperial, Teeside; (7) BP, Grangemouth. 
Table 1 Observed (O) cases, observed/expected (O/E) ratios (95\% CI) of lymphohaematopoietic malignancy within $2 \mathrm{~km}$ and $7.5 \mathrm{~km}$ of industrial complexes that include major oil refineries, and results of Stone's tests

\begin{tabular}{|c|c|c|c|c|c|c|}
\hline \multirow[b]{2}{*}{ Cell type } & \multicolumn{2}{|c|}{$0-2 \mathrm{~km}$} & \multicolumn{2}{|c|}{$0-7.5 \mathrm{~km}$} & \multicolumn{2}{|l|}{ Stone's tests } \\
\hline & $O$ & $O / E(95 \% C I)$ & $O$ & $O / E(95 \% C I)$ & Unconditional $p$ & Conditional $p$ \\
\hline \multicolumn{7}{|l|}{ All ages } \\
\hline All lymphatic and haematopoietic & 417 & $0.95(0.86$ to 1.04$)$ & 3827 & $0.98(0.95$ to 1.01$)$ & 0.64 & 0.51 \\
\hline Multiple myeloma & 57 & $0.74(0.56$ to 0.96$)$ & 625 & $0.89(0.82$ to 0.96$)$ & 0.04 & 0.52 \\
\hline All leukaemias & 169 & $1.06(0.91$ to 1.23$)$ & 1446 & $1.01(0.96$ to 1.07$)$ & 0.58 & 0.78 \\
\hline Lymphoid leukaemias & 71 & $1.00(0.78$ to 1.26$)$ & 597 & $0.94(0.86$ to 1.02$)$ & 0.24 & 0.55 \\
\hline Acute lymphatic leukaemia & 27 & $1.09(0.72$ to 1.59$)$ & 197 & $0.95(0.82$ to 1.09$)$ & 0.24 & 0.17 \\
\hline Chronic lymphatic leukaemia & 42 & $0.99(0.71$ to 1.33$)$ & 364 & $0.91(0.82$ to 1.01$)$ & 0.31 & 0.77 \\
\hline Myeloid leukaemias & 81 & $1.14(0.91$ to 1.42$)$ & 666 & $1.05(0.98$ to 1.14$)$ & 0.31 & 0.38 \\
\hline Acute myeloid leukaemia & 44 & $0.99(0.72$ to 1.33$)$ & 420 & $1.05(0.95$ to 1.16$)$ & 0.57 & 0.50 \\
\hline Chronic myeloid leukaemia & 31 & $1.42(0.97$ to 2.02$)$ & 207 & $1.06(0.92$ to 1.22$)$ & 0.25 & 0.71 \\
\hline Hodgkin's lymphoma & $54 \dagger$ & $1.01(0.76$ to 1.32$)$ & 443 & $0.97(0.89$ to 1.07$)$ & 0.05 & 0.02 \\
\hline Non-Hodgkin's lymphoma & 137 & $0.92(0.77$ to 1.08$)$ & 1313 & $1.00(0.94$ to 1.05$)$ & 0.99 & 0.77 \\
\hline \multicolumn{7}{|l|}{ Ages 0 to 14} \\
\hline All lymphatic and haematopoietic & 25 & $0.99(0.64$ to 1.46$)$ & 180 & $0.93(0.80$ to 1.08$)$ & 0.37 & 0.12 \\
\hline All leukaemias & 19 & $1.00(0.60$ to 1.56$)$ & 138 & $0.94(0.79$ to 1.11$)$ & 0.73 & 0.38 \\
\hline Lymphoid leukaemias & 16 & $1.08(0.62$ to 1.76$)$ & 104 & $0.91(0.74$ to 1.10$)$ & 0.60 & 0.38 \\
\hline Myeloid leukaemias & 2 & $0.66(0.08$ to 2.38$)$ & 22 & $0.93(0.59$ to 1.41$)$ & 0.74 & $\star$ \\
\hline Hodgkin's lymphoma & 2 & $0.77(0.09$ to 2.80$)$ & 18 & $0.89(0.53$ to 1.40$)$ & 0.07 & * \\
\hline Non-Hodgkin's lymphoma & 4 & $1.15(0.31$ to 2.96$)$ & 24 & $0.91(0.58$ to 1.35$)$ & 0.28 & * \\
\hline
\end{tabular}

*Test did not converge because of small numbers

†Includes 1 duplicate registration. Conditional Stone's test for Hodgkin's disease remained significant $(\mathrm{p}=0.03)$ after its exclusion.

\section{Methods}

The study was carried out with the Small Area Health Statistics Unit postcoded health database. It examined cancer risk near all 11 oil refineries in Great Britain, operational by the early 1970s, which processed more than two million tonnes of crude oil in 1993. They were grouped into seven sites of one to three refineries (figure). Each was treated as an extended emissions source. The incidence of lymphohaematopoietic malignancy was examined in eight bands around refinery perimeters with outer limits at $0.5,1,2,3,4.5,5.6,6.6$, and 7.5 $\mathrm{km}$. For descriptive purposes cancer incidence was also examined at $0-2 \mathrm{~km}$ and $0-7.5 \mathrm{~km}$.

The following diagnostic groups of the international classification of diseases 8 th (ICD-8) and 9th (ICD-9) revision were studied for all ages and $0-14,15-64$, and $\geqslant 65$ age groups: lymphatic and haematopoietic malignancy (ICD-8 200-207; ICD-9 200-208，238.6); multiple myeloma (ICD-8 203; ICD-9 203, 238.6) (not separately examined for the $0-14$ age group); non-Hodgkin's lymphoma (ICD-8 and 9 200, 202); Hodgkin's lymphoma (ICD-8 and 9 201); all leukaemias (ICD-8 204-207; ICD-9 204-208); lymphoid leukaemia (ICD-8 and 9 204); and myeloid leukaemia (ICD-8 and 9 205). Acute and chronic subdivisions of the last two were examined for all ages.

Cancer incidence was studied for all years for which national cancer registration data were available: 1974-89 for England and Wales and

Table 2 Observed $(O)$ cases and observed/expected ratios $(O / E)$ by distance from refinery sites: all ages

\begin{tabular}{|c|c|c|c|c|c|c|c|c|}
\hline \multirow{2}{*}{$\begin{array}{l}\text { Outer radius of } \\
\text { band }(\mathrm{km})\end{array}$} & \multicolumn{2}{|c|}{ Multiple myeloma } & \multicolumn{2}{|c|}{ All leukaemias } & \multicolumn{2}{|c|}{ Hodgkin's lymphoma } & \multicolumn{2}{|c|}{$\begin{array}{l}\text { Non-Hodgkin's } \\
\text { lymphoma }\end{array}$} \\
\hline & $O$ & $O / E$ & $O$ & $O / E$ & $O$ & $O / E$ & $O$ & $O / E$ \\
\hline 0.5 & 4 & 0.46 & 14 & 0.74 & $14^{\star}$ & 2.18 & 14 & 0.81 \\
\hline 1 & 8 & 0.58 & 25 & 0.84 & 7 & 0.66 & 23 & 0.81 \\
\hline 2 & 45 & 0.82 & 130 & 1.17 & 33 & 0.91 & 100 & 0.96 \\
\hline 3 & 55 & 0.83 & 137 & 0.99 & 43 & 0.93 & 116 & 0.92 \\
\hline 4.5 & 103 & 0.79 & 275 & 1.02 & 101 & 1.11 & 250 & 1.02 \\
\hline 5.6 & 128 & 0.87 & 316 & 1.07 & 88 & 0.96 & 276 & 1.01 \\
\hline 6.6 & 147 & 1.03 & 279 & 0.96 & 81 & 0.88 & 278 & 1.02 \\
\hline 7.5 & 135 & 0.99 & 270 & 0.99 & 76 & 0.94 & 256 & 1.02 \\
\hline
\end{tabular}

*Includes 1 duplicate registration, exclusion of which reduces the $\mathrm{O} / \mathrm{E}$ ratio within $0.5 \mathrm{~km}$ to 2.02
1975-91 for Scotland. Population counts by band around each site were estimated from census small area statistics with the 1981 census for years up to and including 1986, and the 1991 census thereafter. Expected (E) numbers of cancer registrations were calculated by year and band from annual rates in Great Britain stratified by 5 year age group, sex, and quintile of the Carstairs deprivation index to adjust for possible socioeconomic confounding. ${ }^{11}$ Rates were further adjusted with disease specific standardised regional registration ratios. ${ }^{12} \mathrm{Be}-$ cause of the disparity in years for which cancer registration data were available, national rates for 1974 were computed from 1974 registrations for England and Wales and 1975 registrations for Scotland; and 1990 and 1991 rates were computed from 1989 registrations for England and Wales and those for the relevant year in Scotland.

Formal hypothesis tests were based on the maximum likelihood ratio test of Stone. ${ }^{13}$ This gives a test of decline in risk with distance against a null hypothesis of constant risk in all the bands. As Stone's unconditional test can be significant either where there is a decline in risk with distance or where the relative risk in at least one of the bands does not equal 1.0, we also carried out a conditional test. This specifically tests for decline in risk ${ }^{14}$ and consequently is the test of primary interest. Significance values were based on Monte Carlo methods using 999 simulations. Results from the seven industrial sites were combined by pooling the likelihood ratios from each one and comparing their sum with values obtained from simulated data.

\section{Results}

Results are presented here at all ages and for both sexes combined, and at ages $0-14$ years. Age specific results, and results for each of the seven grouped industrial sites, are available on request. Over all refinery sites combined, there were 417 cases (439.9 expected) of lymphohaematopoeitic malignancy within $2 \mathrm{~km}$ of an oil refinery (observed/expected $(\mathrm{O} / \mathrm{E})$ ratio 
$0.95,95 \%$ confidence interval $(95 \%$ CI) 0.86 to $1.04)$; and 3827 cases (3902.4 expected) within $7.5 \mathrm{~km}(\mathrm{O} / \mathrm{E} 0.98,95 \%$ CI 0.95 to 1.01 , table $1)$. None of the age and cell type specific subgroups separately examined showed a significant increase in risk within $0-2 \mathrm{~km}$ or $0-7.5 \mathrm{~km}$. The conditional Stone's test for Hodgkin's lymphoma, uncorrected for multiple testing, suggested a decline in risk $(\mathrm{p}=0.02)$ with distance from the sites, almost entirely due to an excess within $0.5 \mathrm{~km}\left(14^{\star}\right.$ observed cases, 6.43 expected, table 2). None of the conditional Stone's tests for other malignancies (including Hodgkin's and non-Hodgkin's lymphoma combined) suggested a decline in risk with distance from the sites (tables 1 and 2). The significant $(p=0.04)$ unconditional Stone's test for multiple myeloma at all ages reflected a deficit of these cancers from $0-7.5 \mathrm{~km}$.

\section{Discussion}

Except for Hodgkin's disease, our study provides no evidence to suggest that populations living close to industrial complexes that include large oil refineries in Great Britain have an increased risk of lymphohaematopoeitic malignancy. This is consistent with the findings of broad scale studies of lymphatic and haematopoietic malignancy in areas containing petroleum works in the United States ${ }^{415}$ and with occupational studies of oil refinery workers in the United Kingdom. ${ }^{3}$ Although some studies have reported excesses of leukaemia in refinery workers, ${ }^{16}{ }^{17}$ a recent overview of cohort studies from the United Kingdom and North America suggests no excess for cell type specific leukaemias, ${ }^{18}$ and oil refining probably contributes little to environmental levels of benzene and other petroleum products. ${ }^{19}$

The decline in risk with distance from oil refineries for Hodgkin's disease must be viewed in the context of multiple testing and the general tendency of Hodgkin's disease to cluster. ${ }^{20}$ That benzene might be a contributory factor in Hodgkin's disease has been hypothesised by Aksoy et $a l,{ }^{21}$ and there have been reported associations of Hodgkin's disease with occupation in the chemical industry, ${ }^{22}$ with other occupations entailing handling of chemicals, ${ }^{23-25}$ and with exposure to diesel exhaust. ${ }^{26}$ However, none of these studies provides direct evidence relating to the petrochemical industry. In our study, there was a twofold risk of Hodgkin's disease (14 cases) within $0.5 \mathrm{~km}$ of refineries, and it is this which accounts for the positive Stone's test. This is compatible with a highly localised environmental hazard, although the risk within $2 \mathrm{~km}$ was almost identical to the regional expectation, and it was fractionally below expectation within $7.5 \mathrm{~km}$. There was an unexplained deficit of cases of multiple myeloma within $7.5 \mathrm{~km}$.

${ }^{\star}$ Checks on a sample of cases revealed a duplicate registration of Hodgkin's disease in the 15-64 year age-band within $0.5 \mathrm{~km}$ of a refinery. After exclusion of this duplicate the $\mathrm{O} / \mathrm{E}$ ratio for Hodgkin's disease (all ages) within $2 \mathrm{~km}$ was 0.99 (95\% CI 0.74-1.30); the conditional Stone's test remained significant $(\mathrm{p}=0.03)$.
Limitations to the interpretation of the study are imposed by several factors including lack of exposure information. Measurements of volatile organic compounds, including benzene, near petrochemical plants have been made previously. ${ }^{27}{ }^{28}$ For example, near the Baglan Bay plant, ${ }^{9}$ most of the measurements were $<5$ $\mathrm{ppb},{ }^{28}$ and with exposure to low concentrations of ambient benzene there is great uncertainty about the possible cancer risks. ${ }^{29}$ Other factors limiting interpretation include the small area (ecological) nature of the study, uncertainties about population estimates for years between the census years and migration, and possible unmeasured confounding factors. The results cannot reliably be interpreted for specific cell types and age groups at indivdual sites, given the reliance on routine data sources and the fact that this would depend on multiple and non-independent analyses of subgroups, each with limited statistical power.

Overall the study is estimated to have had $80 \%$ power to detect an excess of around $11 \%$ in lymphohaematopoeitic malignancy at the $5 \%$ level within $2 \mathrm{~km}$ of refineries. We conclude that within the limitations of the small area approach based on routine data sources, there was no significant evidence of association between residence near to industrial sites containing major oil refineries and leukaemias or non-Hodgkin's lymphoma, and there was a negative association with multiple myeloma. Weak evidence of a positive association with Hodgkin's disease needs to be considered within the context of there being little, if any, other epidemiological evidence specifically relating Hodgkin's disease with the petrochemical industry.

This was a Small Area Health Statistics Unit project, supported by the Department of Health, the Department of the Environment, Transport, and the Regions, the Health and Safety ment, Transport, and the Regions, the Health and Safety Executive, Scottish Office Home and Health Department,
Welsh Office, and Northern Ireland Department of Health and Welsh Office, and Northern Ireland Department of Health and
Social Services. The Small Area Health Statistics Unit is funded by grants from the Department of Health, Department of the Environment, Transport and the Regions, Health and Safety Executive, Scottish Office Home and Health Department, Welsh Office, and Northern Ireland Department of Health and Social Services. We thank the Office for National Statistics and the Information and Statistics Division of the Scottish Health Service who made available postcoded cancer data, and, with the help of regional cancer registries, assisted in data checking. We are grateful to representatives of the petrochemical industry and local inspectorates of pollution for providing up to date information on site activities and geographical boundaries. The information on site activities and geographical boundaries. The not necessarily those of the funding departments.

1 Austin H, Delzell E, Cole P. Benzene and leukemia. Am $\mathcal{F}$ Epidemiol 1988;127:419-39.

2 Landrigan PJ. Critical assessment of epidemiologic studies on the human carcinogenicity of 1,3-butadiene. Environ Health Perspect 1990;86:143-8.

3 Rushton L. A 39-year follow-up of the UK oil refinery and distribution center studies: results for kidney cancer and eukaemia. Environ Health Perspect 1993;101(suppl 6):7784.

4 Blot WJ, Brinton LA, Fraumeni JF, et al. Cancer mortality in US counties with petroleum industries. Science 1977;198: $51-3$

5 Gottlieb MS, Shear CL, Seale DB. Lung cancer mortality and residential proximity to industry. Environ Health Perspect 1982;45:157-64

6 Knox EG, Gilman EA. Hazard proximities of childhood cancers in Great Britain 1953-80. F Epidemiol Community Health 1997;51:151-9.

7 Bithell JF, Draper GJ. Apparent association between benzene and childhood leukaemia: methodological doubts concerning a report by Knox. F Epidemiol Community Health 1995;49:437-39.

8 Knox EG, Gilman EA. Migration patterns of children with cancer in Britain. $\mathcal{F}$ Epidemiol Community Health 1998;52: 716-26. 
9 Sans S, Elliott P, Kleinschmidt I, et al. Cancer incidence and mortality near the Baglan Bay petrochemical works, South Wales. Occup Environ Med 1995;52:217-24.

10 Lyons RA, Monaghan SP, Heaven M, et al. Incidence of leukaemia and lymphoma in young people in the vicinity of the petrochemical plant at Baglan Bay, South Wales, 197491. Occup Environ Med 1995;52:225-28.

11 Dolk H, Mertens B, Kleinschmidt I, et al. A standardisation approach to the control of socio-economic confounding in small area studies of environment and health. 7 Epidemio Community Health 1995;49(suppl 2):9-14.

12 Elliott P, Shaddick G, Kleinschmidt I, et al. Cancer incidence near municipal solid waste incinerators in Great Britain. Br 7 Cancer 1996;73:702-10.

13 Bithell JF, Stone RA. On statistical methods for analysing the geographical distribution of cancer cases near nuclear

Shaddick G. Elliott P. Use of Stone's method in studies of disease risk around point sources

15 Heary CD, Ury H, Siegelaub A, et al. Lack of association between cancer incidence and residence near petrochemi$\mathrm{cal}$ industry in the San Fransisco Bay area. $f$ Natl Cancer Inst 1980;64:1295-9.

16 McGraw DS, Joyner RE, Cole P. Excess leukaemia in a refinery population. F Occup Med 1985;27:220-2.

17 Wongsrichanalai C, Delzell E, Cole P. Mortality from leukaemia and other diseases among workers at a petroleum refinery. $\mathcal{F}$ Occup Med 1989;31:106-11.

18 Wong O, Raabe GK. Cell-type-specific leukaemia analyses in a combined cohort of more than 208000 petroleum workers in the United States and the United Kingdom, 1937-89. Regul Toxicol Pharmacol 1995;21:307-21.
19 Wallace LA. Major sources of benzene exposure. Environ Health Perspect 1989;82:165-89.

20 Alexander FE, Williams J, McKinney PA, et al. A specialist leukaemia/lymphoma registry in the UK. Part 2: clustering of Hodgkin's disease. Br f Cancer 1989;60:948-52.

21 Aksoy M, Erdem S, Dinçol K, et al. Chronic exposure to benzene as a possible contributory factor in Hodgkin's disease. Blut 1974;28:293-8.

22 La Vecchia C, Negri E, D'Avanzo D, et al. Occupation and lymphoid neoplasms. Br F Cancer 1989;69:385-8.

23 Olsson H, Brandt L. Occupational handling of chemicals preceding Hodgkin's disease in man. BMF 1979;2:580-1.

24 Olin R. Leukaemia and Hodgkin's disease among Swedish chemistry graduates. Lancet 1976;ii:916.

25 Garland FC, Gorham ED, Garland CF. Hodgkin's disease in the US Navy. Int $\mathcal{F}$ Epidemiol 1987;16:367-72.

26 Boffetta P, Stellman SD, Garfinkel L. Diesel exhaust exposure and mortality among males in the American Cancer Society Prospective Study. Am F Ind Med 1988;14:403-15.

27 Wong O. Bailey WJ. Cancer incidence and community exposure to air emissions from petroleum and chemical plants in Contra Costa County, California: a critical epidemiological assessment. F Environ Health 1993;56:11-17.

28 Bailey J, Campbell G, Kibblewhite M, et al. Air quality audit. BP Chemicals, Baglan Bay. LR 905 (AP/CA). Hertfordshire: Warren Spring Laboratory, 1992. (ISBN 0 856247650 .)

29 United States Environmental Protection Agenct. Carcinogenic effects of benzene: an update. Prepared by the National Center for Environmental Health, Office of Research and Development. Washington, DC: USEPA, 1998. (EPA/600/ P-97/001F.)

\section{Correspondence and editorials}

Occupational and Environmental Medicine welcomes correspondence relating to any of the material appearing in the journal. Results from preliminary or small scale studies may also be published in the correspondence column if this seems appropriate. Letters should be not more than 500 words in length and contain a minimum of references. Tables and figures should be kept to an absolute minimum. Letters are accepted on the understanding that they be subject to editorial revision and shortening.

The journal also publishes editorials which are normally specially commissioned. The Editor welcomes suggestions regarding suitable topics; those wishing to submit an editorial, however, should do so only after discussion with the Editor. 